\title{
OESTRUS SYNCHRONISATION IN POSTPARTUM DAIRY COWS USING REPETITIVE PROSTAGLANDIN DOSES: COMPARISON BETWEEN D-CLOPROSTENOL AND DINOPROST
}

\author{
Carlos Carmelo PÉREZ-MARíN ${ }^{1 *}$, Jose María SÁNCHEZ ${ }^{1}$, Guillermo VIZUETE ${ }^{1}$, \\ Luis Angel QuinTELA ${ }^{2}$ and Laura MOLINA ${ }^{1}$ \\ ${ }^{1}$ Department of Animal Medicine and Surgery, University of Córdoba, Campus de \\ Rabanales, Ctra Madrid-Cádiz km 396, 14071 Córdoba, Spain; ${ }^{2}$ Department of Animal \\ Pathology, University of Santiago de Compostela, Lugo, Spain
}

(Received 22 November 2013; accepted 25 June 2014)

This trial evaluated the reproductive performance in an early routine oestrus induction programme using two different $\mathrm{PGF}_{2 \alpha}$ preparations in dairy cattle. D-cloprostenol sodium $(n=192$; Group A) or dinoprost $(n=187$; Group B) was administered between days 35 and 42 post partum. Also, a group of non-treated cows $(n=135$; Group C) was included as control. Pedometers were used to detect oestrus, and also secondary oestrous signs and vaginal mucus quality were assessed prior to artificial insemination (AI). When oestrus was not detected for 14 days after $\mathrm{PGF}_{2 \alpha}$ administration, the treatment was repeated, up to a maximum of three times. There were no differences between the study groups in oestrus detection $(\mathrm{A}=73.48 \%, \mathrm{~B}=73.01 \%, \mathrm{C}=79.26 \% ; \mathrm{P}=0.428)$, good mucus quality $(\mathrm{A}=$ $96.45 \%, \mathrm{~B}=91.30 \%, \mathrm{C}=93.45 \% ; \mathrm{P}=0.203)$ and the presence of mounting lesions $(\mathrm{A}=98.58, \mathrm{~B}=94.93 \%, \mathrm{C}=98.13 ; \mathrm{P}=0.414)$. First-service pregnancy rates were $19.78 \%, 15.64 \%$ and $32.03 \%$ in Groups A, B and C, respectively $(\mathrm{P}=$ $0.003)$. There were no inter-group differences for the interval from parturition to first AI. However, a significantly shorter interval from parturition to conception (92.17 days, 99.45 days, 118.93 days; $\mathrm{P}=0.002$ ) and significantly less services per conception $(2.12,2.18,2.66 ; \mathrm{P}=0.003)$ were observed in Groups $\mathrm{A}$ and $\mathrm{B}$ in comparison with Group $\mathrm{C}$. The use of $\mathrm{PGF}_{2 \alpha}$ resulted in better fertility in a repetitive, routine postpartum programme, although no differences between Dcloprostenol and dinoprost were detected.

Key words: Oestrus cycle, prostaglandin F2 alpha, reproductive performance, bovine

The use of postpartum oestrus induction and synchronisation programmes has been widely studied to optimise the calving interval and thus increase the

*Corresponding author; E-mail: pv2pemac@uco.es; Phone: 0034 (957) 219-716, Fax: 0034 (957) 211-093 
economic profitability of the herd. It is essential to restore postpartum reproductive status as soon as possible, which is dictated largely by the resumption of hormonal cycling and uterine involution, both of which are in turn regulated by the negative energy balance of this phase (Walsh et al., 2011). The difficulties inherent in postpartum reproductive efficiency are often aggravated by an unacceptably low rate of oestrus detection.

Prostaglandin (PG) treatments have been designed to improve the reproductive results after parturition by the use of, among others, single-dose administration, double-dose administration at 11- to 14-day intervals (Drillich et al., 2000; Répási et al., 2005; Stötzel et al., 2012), or combination of PGs with other active ingredients such as progesterone and GnRH (Pursley et al., 1995; Ribeiro et al., 2012). The currently available PGs differ largely in terms of their molecular composition (Pursley et al., 2012). The efficacy of commercial PGs is a matter of some debate, and depends to a large degree on the speed at which they are metabolised and on their affinity for myometrial and corpus luteum (CL) cellmembrane receptors (Re et al., 1994; Hirsbrunner et al., 1999).

The aim of this prospective study was to compare the effects on reproductive efficiency of a luteolytic dose of D-cloprostenol and dinoprost tromethamine, both of which were routinely administered at 35-42 days postpartum and repeated each 14 days in a commercial dairy cattle farm, as a strategy for improving the reproductive performance in dairy farms.

\section{Materials and methods}

\section{Herd description, animal selection and treatment protocol}

The present study was conducted in a commercial dairy farm with around 1200 lactating Holstein cows, located in Southern Spain (Jaen). The animals were housed in stalls with open-air and sheltered areas and fed a balanced diet, in accordance with the NRC requirements. All cows were milked twice daily at 6:00 and 17:00 h, with an average annual milk yield of $7500 \mathrm{~kg}$ per animal. A voluntary waiting period (VWP) of 35 days was established by selecting all cows at between 35 and 42 days post partum on the day when treatment commenced. Treatment was routinely administered every Monday; in cows not displaying oestrus, treatment was repeated 14 days later, up to a maximum of three times (Fig. 1). Cows were randomly assigned to two treatment groups: Group A ( $\mathrm{n}=$ 192) received $0.15 \mathrm{mg}$ of D-cloprostenol (Dalmazin, Fatro Iberica, Italy) and Group B $(\mathrm{n}=187)$ received $25 \mathrm{mg}$ of dinoprost tromethamine (Dinolytic, Pfizer, Germany). Mean parity was $2.29 \pm 0.94$ in Group A and 2.79 \pm 1.07 in Group B. A total of 135 cows under standard reproductive management, without hormonal treatment for oestrus induction, were included as a control (Group C), with a mean parity of $2.55 \pm 0.97$. Body condition score was $\geq 2.5$ in all animals studied 
(scale 0-5 units; Edmonson et al., 1989). For artificial insemination (AI), pedometers (Dairy Plan, Westfalia, Germany) were used to detect oestrus, which was recorded twice daily, during milking. Before AI, it was also recorded (i) whether cows showed typical oestrous signs on the back and hindquarters caused by scratches from other animals' hooves during mounting, and (ii) whether vaginal mucus, evaluated by vaginal examination, was adequate (abundant, clear, watery vaginal mucus was considered as good quality, and less abundant, thicker mucus was regarded as poor quality). Cows displaying purulent mucus consistent with endometritis were not inseminated. Pregnancy was diagnosed by rectal palpation between 45 and 60 days after insemination. Cows that returned to oestrus following AI or that were not pregnant at the time of diagnosis were not eligible to re-enter the study for subsequent AI.

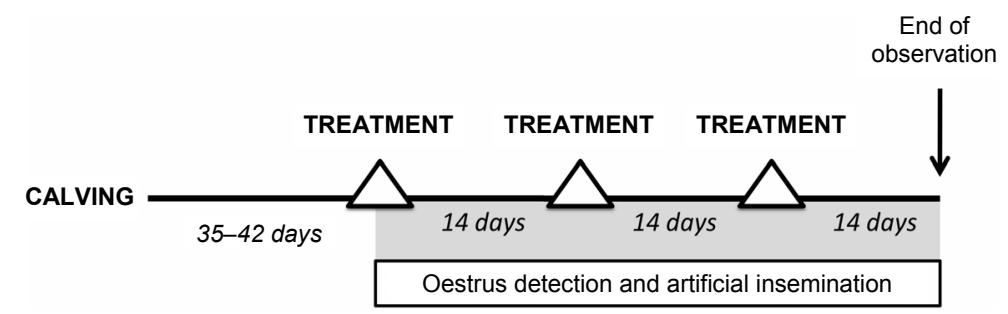

Fig. 1. $\mathrm{PGF}_{2 \alpha}$ schedule used to synchronise oestrus in postpartum dairy cows, indicating the times when oestrus detection and artificial insemination (AI) are carried out

\section{Data management and statistical analysis}

The following calculations were performed for both groups: oestrus detection rate (number of treated cows displaying oestrus), first-service pregnancy rate (number of cows becoming pregnant divided by the number of treated cows), first-service conception rate (number of cows diagnosed pregnant divided by the number of cows inseminated), percent of cows displaying oestrus with abundant and clear vaginal mucus, percent of cows displaying oestrus with typical oestrusrelated signs on back and hindquarters, interval from parturition to first AI, interval from parturition to conception (days open) by 200 days, and services/ gestation (by 200 days). Chi-square test was used to compare proportions, while intervals were compared by analysis of variance (ANOVA) and when differences were significant $(\mathrm{P} \leq 0.05)$, the Least Square Differences (LSD) test was performed. Results were expressed as mean \pm SD. Survival curves were used to show the proportion of cows that did not demonstrate oestrus (and were not inseminated), and that did not conceive during the period of study. The statistical software package SPSS 11.0 for Windows was used to perform statistical analyses. 


\section{Results}

No significant differences for oestrus detection rates were observed following the administration of D-cloprostenol or dinoprost, or in Group C $(73.48 \%, 73.01 \%$ and $79.26 \%$, respectively; $\mathrm{P}=0.428)$. Figure 2 shows differences in the time elapsing to first AI (i.e. observed oestrus). Table 1 shows oestrus detection rates after the first, second and third prostaglandin administrations, where no inter-group differences were observed. In relation to the quality and quantity of cervical mucus at oestrus, largely abundant, clear and watery mucus was observed in $96.45 \%(136 / 141)$ of oestrous cows treated with D-cloprostenol, in $91.30 \%(126 / 138)$ of cows in the dinoprost tromethamine group, and in $93.45 \%(100 / 107)$ in the non-treated group; the differences were not significant $(\mathrm{P}=0.203)$ (Table 1). The percentage of cows in which pedometer-detected oestrus was accompanied by mounting lesions did not show treatment-related variation $(\mathrm{A}=98.58 \%, \mathrm{~B}=94.93 \%, \mathrm{C}=98.13 \% ; \mathrm{P}=0.414)$. A total of 13 cows $(2.7 \%)$ were excluded from the treated groups (5 from Group A and 8 from Group B) due to vaginal discharge consistent with endometritis, while 7 cows were excluded from the non-treated group.

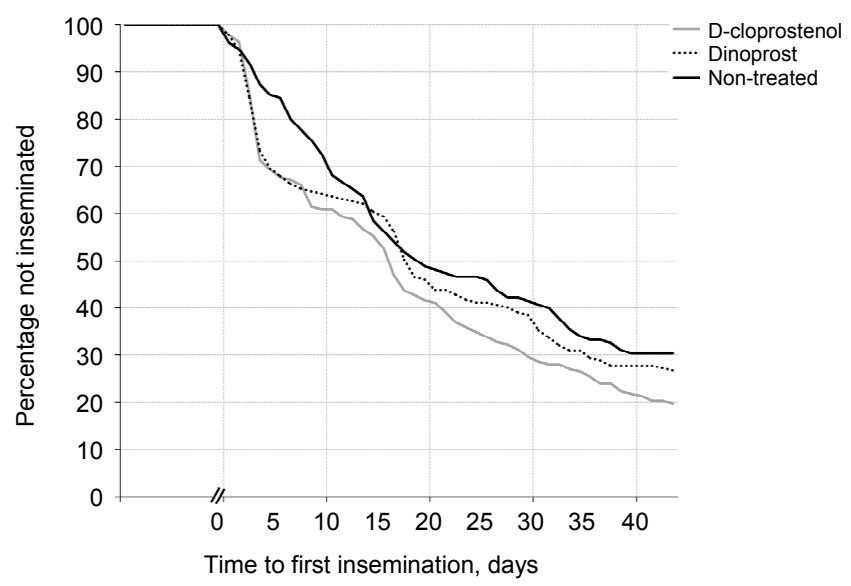

Fig. 2. Survival curves for days to first AI in dairy cows that were treated with D-cloprostenol $(\mathrm{n}=192$, grey line), dinoprost $(\mathrm{n}=187$, dashed line $)$ or were left without treatment $(\mathrm{n}=135$, black line). There was no difference for the interval from parturition to first AI between groups. Day 0 indicates the beginning of the $\mathrm{PGF}_{2 \alpha}$ treatment or the voluntary waiting period (VWP) in the nontreated group (day 35 after parturition)

Overall first-service pregnancy rate was similar in Groups A and B $(19.78 \%$ and $15.64 \%$, respectively; Table 1 ), while Group $\mathrm{C}$ showed a significantly higher value $(32.03 \% ; \mathrm{P}=0.003)$. Cows showing oestrus after $\mathrm{PGF}_{2 \alpha}$ treatments had a significantly lower $(\mathrm{P}=0.007)$ percentage of pregnancies $(26.24 \%$ and $20.29 \%$ in 
Table 1

Mean percentage of oestrus detection, presence of mounting lesions and vaginal mucus, and conception and pregnancy rates in postpartum dairy cows treated with different $\mathrm{PGF}_{2 \alpha}$ until oestrus induction

\begin{tabular}{|c|c|c|c|c|}
\hline \multirow{2}{*}{$\mathrm{PGF}_{2 \alpha}$ treatments for oestrus induction } & \multicolumn{3}{|c|}{ Treatment groups } & \multirow{2}{*}{ P valu } \\
\hline & D-cloprostenol & Dinoprost & Non-treated & \\
\hline \multicolumn{5}{|l|}{ At first treatment } \\
\hline Detected oestrus rate $(\%$, number $)$ & $40.10(77 / 192)$ & $40.64(76 / 187)$ & - & 0.917 \\
\hline First-service conception rate ( $\%$, number) & $10.94(21 / 192)$ & $8.02(15 / 187)$ & - & 0.382 \\
\hline First-service pregnancy rate $(\%$, number $)$ & $27.27(21 / 77)$ & $19.73(15 / 76)$ & - & 0.341 \\
\hline \multicolumn{5}{|l|}{ At second treatment } \\
\hline Detected oestrus rate $(\%$, number $)$ & $38.26(44 / 115)$ & $36.93(41 / 111)$ & - & 0.891 \\
\hline First-service conception rate (\%, number) & $10.43(12 / 115)$ & $8.18(9 / 111)$ & - & 0.648 \\
\hline First-service pregnancy rate $(\%$, number $)$ & $27.27(12 / 44)$ & $21.95(9 / 41)$ & - & 0.621 \\
\hline \multicolumn{5}{|l|}{ At third treatment } \\
\hline Detected oestrus rate $(\%$, number$)$ & $31.25(20 / 64)$ & $30.0(21 / 70)$ & - & 1.00 \\
\hline First-service conception rate $(\%$, number $)$ & $6.25(4 / 64)$ & $5.7(4 / 70)$ & - & 1.00 \\
\hline First-service pregnancy rate $(\%$, number $)$ & $20.00(4 / 20)$ & $19.04(4 / 21)$ & - & 1.00 \\
\hline \multicolumn{5}{|l|}{ Overall } \\
\hline Detected oestrus rate $(\%$, number $)$ & $73.48(141 / 192)$ & $73.01(138 / 187)$ & $79.26(107 / 135)$ & 0.428 \\
\hline Adequate mucus $(\%$, number $)$ & $96.45(136 / 141)$ & $91.30(126 / 138)$ & $93.45(100 / 107)$ & 0.203 \\
\hline Mounting lesions $(\%$, number $)$ & $98.58(139 / 141)$ & $94.93(131 / 138)$ & $98.13(105 / 107)$ & 0.414 \\
\hline First-service pregnancy rate $(\%$, number $)$ & $19.78(37 / 187)^{\mathrm{a}}$ & $15.64(28 / 179)^{\mathrm{a}}$ & $32.03(41 / 128)^{\mathrm{b}}$ & 0.003 \\
\hline First-service conception rate ( $\%$, number $)$ & $26.24(37 / 141)^{\mathrm{a}}$ & $20.29(28 / 138)^{\mathrm{a}}$ & $38.32(41 / 107)^{\mathrm{b}}$ & 0.007 \\
\hline Open days & $92.17 \pm 43.36^{\mathrm{a}}$ & $99.45 \pm 57.54^{\mathrm{a}}$ & $118.93 \pm 74.32^{b}$ & 0.002 \\
\hline Days to first AI & $52.24 \pm 12.38$ & $54.67 \pm 39.67$ & $62.21 \pm 45.62$ & 0.137 \\
\hline Number of AIs to pregnancy & $2.12 \pm 1.14^{\mathrm{a}}$ & $2.18 \pm 1.32^{\mathrm{a}}$ & $2.66 \pm 1.58^{\mathrm{b}}$ & 0.002 \\
\hline
\end{tabular}


Group A and Group B, respectively) than cows included in Group C (38.32\%) during the period of the treatment, i.e. $80( \pm 3)$ days after calving (Table 1). There were no inter-group differences for the interval from parturition to first AI $(\mathrm{A}=52.24 \pm 12.38 ; \mathrm{B}=54.67 \pm 39.67 ; \mathrm{C}=62.21 \pm 45.62 ; \mathrm{P}=0.137)$. In Groups $\mathrm{A}$ and $\mathrm{B}$, cows needed fewer services to get pregnant than in Group C $(2.12 \pm$ $1.14 ; 2.18 \pm 1.32 ; 2.66 \pm 1.58$, respectively; $\mathrm{P}=0.0031$ ). The number of open days was significantly lower in Groups A and B than in Group C (92.17 \pm 43.36 days and $99.45 \pm 57.54$ days, versus $118.93 \pm 74.32$ days, respectively; $\mathrm{P}=0.002$ ).

\section{Discussion}

When selecting routine postpartum treatment schedules, priority must be given to the ease of use, scheduling convenience, clinical efficacy and cost effectiveness of the product. The final treatment choice will depend on the particular characteristics and purposes of the farm. Timed breeding systems are beneficial to the management of reproduction of dairy cows because they make it possible to schedule and control the insemination programme of lactating dairy cows. Repeated administration of $\mathrm{PGF}_{2 \alpha}$ is one of the most widely used treatments (Tenhagen et al., 2000). Therefore, oestrus synchronisation programmes should aim to control the follicular waves as well as the onset of oestrus and ovulation (Alnimer et al., 2009), in order to improve the oestrus detection and the pregnancy rates (Pankowski et al., 1995; Bissinoto and Santos, 2012). The results obtained in this study confirm that repetitive administration of D-cloprostenol achieves slightly better reproductive rates compared to dinoprost tromethamine, although the differences were not significant. In a similar study, Pursley et al. (2012) observed that differences between the two $\mathrm{PGF}_{2 \alpha}$ products were really apparent in first-parity cows.

After routine administration every 14 days, D-cloprostenol and dinoprost tromethamine proved equally effective in achieving synchronised oestrus induction in lactating dairy cows. Oestrus detection rates obtained with both $\mathrm{PGF}_{2 \alpha}$ products were higher than those reported in previous trials by Momcilovic et al. (1998) or Pursley et al. (2012) (52\% and 46.7\%, respectively), and a decline in oestrus detection rates after each successive dose of $\mathrm{PGF}_{2 \alpha}$ was observed. Animals failing to display oestrus after treatment should be further examined to ascertain the reason for the absence of oestrus.

Both studied PGs produced abundant, clear cervical mucus, perhaps due to an improved $\mathrm{PGF}_{2 \alpha}$-mediated follicular growth (Armstrong, 1981) and by the enhancement of oestradiol and LH secretion (Tsiligianni et al., 2001). Whether PGs have direct effects on follicular growth prior to the LH surge to initiate ovulation in livestock is unknown, but $\mathrm{PGF}_{2 \alpha}$ increases pituitary responsiveness to 
GnRH to release LH in the postpartum cow (Weems et al., 2006). A very high proportion of cows detected in oestrus by pedometer showed mounting lesions. The results suggest that if this working protocol is adopted, the reproductive efficiency can be improved even in herds that use visual observation to detect oestrus. Although physical differences in cervical mucus quality are not believed to directly affect fertility (Tsiligianni et al., 2001), the results suggest that abundant, clear mucus may serve as an indicator of oestrus in farms using oestrus detection by observation, and may enable the timing of AI to be optimised. Similarly, $\mathrm{PGF}_{2 \alpha}$ administration leads to improved oestrus detection rates, since the number of mountings increases with the number of animals displaying oestrus, due to behavioural and pheromonal interactions. The increase in oestrous behaviour associated with more cows in oestrus could increase the number of oestrous cows detected with infrequent visual observation (Floyd et al., 2009).

At the onset of oestrus, $2.7 \%$ of the treated cows displayed whitish speckled cervical mucus consistent with genital infection. This rate is lower than the $15.6 \%$ reported by Drillich et al. (2000). According to Gautam et al. (2010), $25.3 \%$ of cows with postpartum endometritis (clinical or subclinical) during days 15 to 60 had persistence or recurrence of endometritis between days 61 and 150 . This suggests that the repeated administration of $\mathrm{PGF}_{2 \alpha}$ outlined here is not only an efficient tool for oestrus induction and synchronisation, but may also have a therapeutic effect on mild (undetected) endometritis and thus enhance reproductive efficiency (Knutti et al., 2000; Tenhagen et al., 2001). The use of $\mathrm{PGF}_{2 \alpha}$ has also been described for treating subclinical endometritis (Janowski et al., 2011). However, the above-mentioned treatment sometimes does not affect the prevalence of subclinical endometritis, although it increases first-service pregnancy per AI (Galvão et al., 2009).

In both treated groups, oestrus distribution was highly heterogeneous, similarly as reported by Seguin et al. (1985), since follicular development was not controlled and maximum frequency of onset was recorded around 3 days after treatment, in agreement with the findings of LeBlanc et al. (1998). One factor limiting the efficacy of the repeat-dose $\mathrm{PGF}_{2 \alpha}$ protocol was the considerable variation of ovulation time, which rendered fixed-time AI impossible (Keister et al., 1999). A recurring doubt is whether or not the use of $\mathrm{PGF}_{2 \alpha}$ has a negative effect on fertility, due to either incomplete luteolysis or interference of the protocol with follicular dynamics. Lauderdale et al. (1974) and Drillich et al. (2000) deny the existence of any such negative effect. Minor improvements in pregnancy rates are proof enough to justify the financial benefits of using $\mathrm{PGF}_{2 \alpha}$ treatments (Plunkett et al., 1984). Treatment with additional $\mathrm{PGF}_{2 \alpha}$ increased the percentage of cows that have completed luteal regression but it did not have a detectable effect on pregnancies per AI (Brusveen et al., 2009).

In this study, it was observed that the first-service conception rate using D-cloprostenol was slightly higher than that obtained using dinoprost tro- 
methamine, and similar as reported by others (Momcilovic et al., 1998; Keister et al., 1999; Drillich et al., 2000), although protocols differed between studies. In contrast, other studies concluded that both products were equally effective luteolysins and produced similar pregnancy outcomes in lactating dairy cows (Stevenson and Phatak, 2010). Cairoli et al. (2006) found no differences in conception rates between cloprostenol and dinoprost in cows inseminated at observed oestrus. In agreement with the findings of the present study, Salverson et al. (2002) reported that following administration of PGF $_{2 \alpha}$ (dinoprost and racemic cloprostenol) in combination with MGA, the oestrus synchronisation and fertility results were similar for the two prostaglandins.

A number of studies report that the fertility rates obtained after routine administration of $\mathrm{PGF}_{2 \alpha}$ with no prior animal examination are higher than those obtained following administration of $\mathrm{PGF}_{2 \alpha}$ when a CL is detected by rectal palpation (Kristula et al., 1992; Heuwieser et al., 1997; Répási et al., 2014) or when high progesterone levels are measured (Heuwieser et al., 1997). In other studies, the accuracy of rectal palpation for the presence of a functional CL was $73.9 \%$, which confirms the unreliability of rectal palpation alone to assess the functionality of the CL (Cairoli et al., 2006).

Cows included in Groups A and B required further 20 days to get pregnant in comparison with those in Group $\mathrm{C}$, which represents a considerable financial drain. Knutti et al. (2000) observed that the interval between parturition and conception in cows with mild endometritis was shorter in non-cycling cows treated with $\mathrm{PGF}_{2 \alpha}$ than in cycling herdmates, but not significant differences were detected. This finding would seem to further highlight the advantages of the breeding programme mentioned here. No inter-group differences were observed in the interval between calving and first insemination. The interval was relatively short in both treated groups, thus allowing conception to take place sooner, and enabling cows with reproductive disorders to be treated earlier. In contrast to the findings of Revah et al. (1989), repeated administration of $\mathrm{PGF}_{2 \alpha}$ reduced the number of services required for the cow to become pregnant, thus underlining again the positive effect of $\mathrm{PGF}_{2 \alpha}$ on fertility.

In conclusion, the results obtained in this study demonstrate that routine postpartum administration of prostaglandins is a viable working protocol for commercial dairy farms with a high-quality oestrus detection system, enabling improved oestrus detection, concentration of $\mathrm{AI}$ and enhanced breeding efficiency, and significant differences between natural and synthetic $\mathrm{PGF}_{2 \alpha}$ were not detected in terms of the results achieved. 


\section{References}

Alnimer, M., Tabbaa, M. J., Ababneh, M. M. and Lubbadeh, W. F. (2009): Applying variations of the Ovsynch protocol at the middle of the estrus cycle on reproductive performance of lactating dairy cows during summer and winter. Theriogenology 72, 731-740.

Armstrong, D. T. (1981): Prostaglandins and follicular function. J. Reprod. Fertil. 62, 283-291.

Bissinoto, R. S. and Santos, J. E. P. (2012): The use of endocrine treatments to improve pregnancy rates in cattle. Reprod. Fertil. Dev. 24, 258-266.

Brusveen, D. J., Souza, A. H. and Wiltbank, M. C. (2009): Effects of additional prostaglandin $F_{2 \alpha}$ and estradiol-17 $\beta$ during Ovsynch in lactating dairy cows. J. Dairy Sci. 92, 1412-1422.

Cairoli, F., Mollo, A., Veronesi, M. C., Renaville, B., Faustini, M. and Battocchio, M. (2006): Comparision between cloprostenol-induced and spontaneus oestrus fertility in dairy cows. Reprod. Domest. Anim. 41, 175-179.

Drillich, M., Tenhagen, B.-A. and Heuwieser, W. (2000): Effect of one spontaneous estrus cycle (after synchronization with PGF2 $\alpha$ ) on reproductive performance in dairy cows. Theriogenology 54, 1389-1394.

Edmonson, A. J., Lean, I. J., Weaver, L. D., Farver, T. and Webster, G. (1989): A body condition scoring chart for Holstein dairy cows. J. Dairy Sci. 72, 68-78.

Floyd, L. N., Lents, C. A., White, F. J. and Wettemann, R. P. (2009): Effect of number of cows in estrus and confinement area on estrous behavior of beef cows. J. Dairy Sci. 87, 1998-2004.

Galvão, K. N., Frajblat, M., Brittin, S. B., Butler, W. R., Guard, C. L. and Gilbert, R. O. (2009): Effect of prostaglandin $\mathrm{F}_{2 \alpha}$ on subclinical endometritis and fertility in dairy cows. J. Dairy Sci. 92, 4906-4913.

Gautam, G., Nakao, T., Koike, K., Long, S. T., Yusuf, M., Ranasinghe, R. M. and Hayashi, A. (2010): Spontaneous recovery or persistence of postpartum endometritis and risk factors for its persistence in Holstein cows. Theriogenology 73, 168-179.

Heuwieser, W., Oltenacu, P. A., Lednor, A. J. and Foote, R. H. (1997): Evaluation of different protocols for prostaglandin synchronization to improve reproductive performance in dairy herds with low estrus detection efficiency. J. Dairy Sci. 80, 2766-2774.

Hirsbrunner, G., Küpfer, U., Burkhardt, H. and Steiner, A. (1999): Effect of different prostaglandins on intrauterine pressure and uterine motility during dioestrus in experimental cows. Tierarztl. Umsch. 54, 624-630.

Janowski, T., Zduńczyk, S. and Barański, W. (2011): Subclinical endometritis as a cause of insemination failure in dairy cows. Med. Weter. 67, 79-82.

Keister, Z. O., Dense, S. K., Armstrong, D. V., Ax, R. L. and Brown, M. D. (1999): Pregnancy outcomes in two comercial dairy herds following hormonal scheduling programs. Theriogenology 51, 1587-1596.

Knutti, B., Küpfer, U. and Busato, A. (2000): Reproductive efficiency of cows with endometritis after treatment with intrauterine infusions or prostaglandin injections, or no treatment. J. Vet. Med. A 47, 609-615.

Kristula, M., Bartholomew, R., Galligan, D. and Uhlinger, C. (1992): Effects of a prostaglandin F2 alpha synchronization program in lactating dairy cattle. J. Dairy Sci. 75, 2713-2718.

Lauderdale, J. W., Seguin, B. E., Stellflu, J. N., Chenault, J. R., Thatcher, W. W., Vincent, C. K. and Loyancano, A. F. (1974): Fertility of cattle following PGF2 $\alpha$ injection. J. Dairy Sci. 38, 964-967.

LeBlanc, S. J., Leslie, K. E., Ceelen, H. J., Kelton, D. F. and Keefe, G. P. (1998): Measures of estrus detection and pregnancy in dairy cows after administration of gonadotropin-releasing hormone within an estrus synchronization program based on prostaglandin F2 alpha. J. Dairy Sci. 81, 375-381.

Momcilovic, D., Archbald, L. F., Walters, A., Tran, T., Kelbert, D., Risco, C. and Thatcher, W.W. (1998): Reproductive performance of lactating dairy cows treated with gonadotrophin- 
releasing hormone $(\mathrm{GnRH})$ and/or prostaglandin F2 $\alpha$ (PGF2 $\alpha$ ) for synchronization of estrus and ovulation. Theriogenology 50, 1131-1139.

Pankowski, J. W., Galton, D. M., Erb, H. N., Guard, C. L. and Gröhn, Y. T. (1995): Use of prostaglandin F2 $\alpha$ as a postpartum reproductive management tool for lactating dairy cows. J. Dairy Sci. 78, 1477-1488.

Plunkett, S. S., Stevenson, J. S. and Call, E. P. (1984): Prostaglandin F2 $\alpha$ for lactating dairy cows with palpable corpus luteum but unobserved estrus. J. Dairy Sci. 67, 380-387.

Pursley, J. R., Martins, J. P. N., Wright, N. D. and Stewart, N. D. (2012): Compared to dinoprost tromethamine, cloprostenol sodium increased rates of estrus detection, conception and pregnancy in lactating dairy cow on a large commercial dairy. Theriogenology 78, 823-829.

Pursley, J. R., Mee, M. O. and Wiltbank, M. C. (1995): Synchronization of ovulation in dairy cows using PGF2 $\alpha$ and GnRH. Theriogenology 44, 915-923.

Re, G., Badino, P., Novelli, A., Vallisneri, A. and Girardi, C. (1994): Specific binding of dlcloprostenol and D-cloprostenol to PGF alpha receptors in bovine corpus luteum and myometrial cell membranes. J. Vet. Pharmacol. Ther. 17, 455-458.

Répási, A., Beckers, J. F., Sulon, J., Karen, A., Reiczigel, J. and Szenci, O. (2005): Effect of the type and number of prostaglandin treatments on corpus luteum, the largest follicle and progesterone concentration in dairy cows. Reprod. Domest. Anim. 40, 436-442.

Répási, A., Szelényi, Z., Reiczigel, J., Bajcsy, Á. Cs., Horváth, A. and Szenci, O. (2014): Control of ovulation after prostaglandin treatment by means of ultrasonography and effect of the time of ovulation on conception rate in dairy cows. Acta Vet. Hung. 62, 74-83.

Revah, I., Lomas, R., Zarco, L. and Galina, C. (1989): Evaluación del tratamiento rutinario con prostaglandina $\mathrm{F} 2 \alpha$ en el día 30 o 40 postparto sobre la actividad ovárica y la eficacia reproductiva de las vacas Holstein [Evaluation of the effect of routine treatment with prostaglandin F2 $\alpha$ on postpartum days 30 or 40 on ovarian activity and reproductive efficiency of Holstein cows (in Spanish)]. Vet. Méx. 20, 135-143.

Ribeiro, E. S., Bisinotto, R. S., Favoreto, M. G., Martins, L. T., Cerri, R. L. A., Silvestre, F. T., Greco, L. F., Thatcher, W. W. and Santos, J. E. P. (2012): Fertility in dairy cows following presynchronization and administering twice the luteolytic dose of prostaglandin F2 $\alpha$ as one or two injections in the 5-day timed artificial insemination protocol. Theriogenology 78, 273-284.

Salverson, R. R., deJarenette, J. M., Marshall, C. E. and Wallace, R. A. (2002): Synchronization of estrus in virgin beef heifers using melengestrol acetate and PGF2 $\alpha$ : an efficacy comparison of cloprostenol and dinoprost tromethamine. Theriogenology 57, 853-858.

Seguin, B., Momont, H. and Baumann, L. (1985): Cloprostenol and dinoprost tromethamine in experimental and field trials treating unobserved estrus in dairy cows. Bovine Pr. 20, 85-90.

Stevenson, J. S. and Phatak, A. P. (2010): Rates of luteolysis and pregnancy in dairy cows after treatment with cloprostenol or dinoprost. Theriogenology 73, 1127-1138.

Stötzel, C., Plöntzkeb, J. and Röblitz, S. (2012): Advances in modeling of the bovine estrous cycle: Synchronization with PGF2. Theriogenology 78, 1415-1428.

Tenhagen, B. A., Birkelbach, E. and Heuwieser, W. (2000): Serum progesterone levels in postpartum dairy cows after repeated application of the prostaglandin F2 $\alpha$ analogue D $(+)$ cloprostenol sodium. J. Vet. Med. A 47, 213-220.

Tenhagen, B. A., Drillich, M. and Heuwieser, W. (2001): Analysis of cow factors influencing conception rates after two timed-breeding protocols. Theriogenology 56, 831-839.

Tsiligianni, Th., Karagiannidis, A., Brikas, P. and Saratsis, Ph. (2001): Physical properties of bovine cervical mucus during normal and induced (progesterone and/or PGF2 $\alpha$ ) estrus. Theriogenology 55, 629-640.

Walsh, S. W., Williams, E. J. and Evans, A. C. O. (2011): A review of the causes of poor fertility in high milk producing dairy cows. Anim. Reprod. Sci. 123, 127-138.

Weems, C. W., Weems, Y. S. and Randel, R. D. (2006): Prostaglandins and reproduction in female farm animals. Vet. J. 171, 206-228. 